\title{
Expansión urbana en las áreas litorales de América Latina y Caribe $^{1}$
}

\author{
Juan Manuel Barragán² y María de Andrés ${ }^{3}$
}

\begin{abstract}
RESUMEN
Las áreas litorales de América Latina y Caribe (ALC) se encuentran cada vez más afectadas por los asentamientos humanos. La expansión urbana conlleva un importante cambio en los usos del suelo, especialmente sobre el litoral. La presente investigación analiza este proceso desde un punto de vista cualitativo y cuantitativo. Se estudia la evolución de la población en todas las ciudades de ALC mayores a 100.000 habitantes, litorales e interiores entre 1945 y 2014. El método empleado relaciona diferentes fuentes de información de las bases de datos de Naciones Unidas con las imágenes de sensores remotos de Google Earth. De esta forma es posible perfilar ciertos fenómenos urbanos y costeros en ALC. Los resultados muestran un litoral de ciudades pequeñas y próximas a unidades fisiográficas y ecosistemas vulnerables como bahías, estuarios o bosques de manglar. El resultado obtenido pone de manifiesto algunas prioridades de gestión para las áreas litorales en la región de ALC.
\end{abstract}

Palabras clave: América Latina y Caribe, ciudades costeras, cambio litoral, ecosistemas costeros, presiones urbanas

\begin{abstract}
Coastal areas in Latin America and the Caribbean (LAC) are increasingly affected by human settlements. Urban expansion involves a significant change in land use, especially in the coastal area. This research analyses this process from a qualitative and quantitative perspective. Population evolution is studied in all LAC cities with greater than 100,000 inhabitants, differentiating the coastal cities and the interior ones, from 1945 to 2014. The method relates different information sources; from United Nations databases and images from remote sensing. This allows obtaining different urban and coastal process in Latin America and the Caribbean. The results show a coastal area with small cities located close to fragile ecosystems, such as bays, estuaries and mangrove forests. Results obtained highlight management priorities for coastal areas in the LAC region.
\end{abstract}

Key words: Latin America and the Caribbean, coastal cities, littoral change, coastal ecosystems, urban pressure.

\footnotetext{
1 Artículo recibido el 11 de mayo de 2015, aceptado el 4 de noviembre de 2015 y corregido el 18 de noviembre de 2015 .

2 Universidad de Cádiz / Grupo de Gestión Integrada de Áreas Litorales (España).

E-mail: juan.barragan@uca.es
}

\footnotetext{
3 Universidad de Cádiz / Grupo de Gestión Integrada de Áreas Litorales (España).

E-mail:maria.deandres@uca.es
} 
La población mundial se encuentra en continuo y rápido crecimiento. Esta asciende en 2013 a 7.124 millones de habitantes (World Bank, 2014: 4), mientras que en 2000 era de 6.000 millones. Además, este aumento tiene lugar sobre todo en ciudades y en áreas litorales (Barragán \& de Andrés, 2015a; McGranahan, et al., 2007; Mulligan \& Crampton, 2005; Small \& Nicholls, 2003a) Aglomeraciones urbanas costeras como la de Tokio (38 millones de habitantes), Shanghai (23 millones), Bombay (21 millones) o São Paulo (21 millones), por ejemplo, registran concentraciones demográficas nunca vistas con anterioridad (UN-DESA, 2014).

Las áreas litorales han constituido, a lo largo de la historia, un ámbito favorable para el asentamiento de la población por las actividades humanas. Diferentes autores y organizaciones internacionales así lo han puesto de manifiesto (Burke et al., 2001: 6; Creel, 2003: 2; Hinrichsen, 1998: 24; PNUMA, 2003: 109; Vallega, 1999: 98). El proceso de expansión urbana y el crecimiento urbano asociado es especialmente importante en América Latina y Caribe (ALC). En 2014 la población urbana de ALC alcanza casi los 500 millones de habitantes (UN-DESA, 2014: 25), considerándose la región del mundo en desarrollo con un mayor porcentaje de población urbana (PNUMA, 2010: 27). Además, por razones históricas, el origen de la expansión urbana de esta región se sitúa en la franja litoral (Barragán, 2012: 12). Este patrón de ocupación del territorio se remonta a la época colonial, periodo en el que la costa era un ámbito geográfico estratégico para sus antiguas metrópolis, lo que explica una elevada concentración de la población, de la actividad económica y, por tanto, de las ciudades (Hardoy, 1974: 13; UN-Habitat, 2000: 11). El crecimiento demográfico origina una constante presión sobre el espacio litoral. Un estudio del WRI (World Resources Institute) muestra, por ejemplo, que en 1995 el $29 \%$ de las zonas costeras en Mesoamérica y el $50 \%$ en Suramérica se encontraban bajo una amenaza media-alta. Dicho estudio se basaba, fundamentalmente, en indicadores de carácter urbano; ello pone de manifiesto la importancia del proceso urbanizador sobre el litoral de ALC.

Los ecosistemas costero marinos de América Latina y Caribe tienen una gran importancia desde el punto de vista ambiental y desde una perspectiva socioeconómica. Los servicios ecosistémicos de manglares y arrecifes de coral, por ejemplo, están muy vinculados a las economías locales. Esto justifica que la población tienda a asentarse próxima a ellos, ejerciendo una importante presión y comprometiendo, en demasiadas ocasiones, la salud de dichos ecosistemas y la de sus servicios (Scherer et al., 2014; Agardy et al., 2005: 517). Además, los procesos informales de ocupación de terrenos públicos (espacios intermareales o de borde costero, por ejemplo) constituyen un factor explicativo añadido donde la pobreza y el riesgo son aspectos esenciales de un proceso nada singular en países con notable inequidad de bienestar humano (Barragán, 2012). Se trata, en síntesis, del círculo de insostenibilidad que presentan algunos patrones de desarrollo.

La presente investigación tiene como objetivo fundamental perfilar el modelo de expansión y crecimiento urbanos de ALC, en su relación con los espacios y ecosistemas costeros, interpretando siempre en este trabajo el término modelo como esquema o abstracción de una realidad determinada cambiante. Para ello se parte del análisis de la evolución de las ciudades costeras del mundo, aunque se centra, y profundiza, en las características especiales de la región. Además se lleva a cabo un estudio del poblamiento costero urbano de ALC en las últimas siete décadas (19452014). En primer lugar, se compara el poblamiento de ALC con el del resto del mundo. Posteriormente, se detalla la ocupación del territorio costero en la región. La segunda parte del trabajo cuantifica la magnitud del asentamiento urbano con respecto a los ecosistemas costero marinos más relevantes (se han elegido manglares y arrecifes de coral a modo de ejemplos). También se establece relación entre las actividades económicas asociadas al ámbito urbano y las presiones detectadas sobre la base natural. Los resultados de la investigación permiten cuantificar el fenómeno urbanizador sobre el litoral de ALC, así como sus implicaciones respecto a los ecosistemas costeros marinos del entorno próximo.

\section{Fuentes de información y método de la investigación}

Para el desarrollo de este trabajo se han utilizado tres fuentes de información. La primera 
corresponde a las bases de datos de las Naciones Unidas (Demographic Yearbook), que ofrece datos de población de todas las ciudades mayores a 100.000 habitantes. La definición de ciudad y aglomeración urbana utilizadas son las que se establecen desde las Naciones Unidas (UN-DESA, 2013). La segunda fuente es Google Earth. Las imágenes desde sensores remotos ofrecen un gran detalle para la observación y concreción física de los ámbitos urbanos. La información geográfica aportada por UNEP, a través del World Conservation Monitoring Centre (WCMC), constituye la tercera fuente de información. Las capas de los ecosistemas costero marinos en ALC permiten relacionar estos ecosistemas con la expansión urbana. Aunque todas estas son utilizadas de forma independiente por diferentes investigadores (Angel \& Sheppard, 2005; McGranahan \& Marcotullio, 2004), es muy interesante la relación que se establece entre ellas en el presente trabajo. Entre otras razones porque permite caracterizar mejor ciertos aspectos del poblamiento litoral. La importancia del método utilizado recae en la sencillez de su utilización y en el detalle que ofrecen cuando se combinan las fuentes de información.

El método de trabajo desarrollado ejecuta las siguientes tareas:

a. Obtener, organizar y analizar la información de las bases de datos. Estas contienen información de 764 ciudades y aglomeraciones urbanas en ALC con más de 100.000 habitantes entre 1945 y 2012. Además, se ha utilizado la información de los censos nacionales de población para completar los datos actualizados hasta 2014.

Diferenciar entre ciudades litorales e interiores. Para ello, se han seleccionado aquellas ciudades que están a menos de 100 km desde la línea de costa. Las Ciudades y Aglomeraciones Costeras (CACs) incluyen tanto a las ciudades en sus límites administrativos como a las aglomeraciones, según los criterios de Naciones Unidas (UN-DESA, 2013). Si una ciudad se encuentra en una isla, siguiendo los criterios del PNUMA (Dahl, 1995), también se ha considerado costera incluso si está a más de 100 km. La distancia de 100 km es elegida en la Evaluación de Ecosis- temas del Milenio para delimitar la zona costera (Agardy et al., 2005).

b. Describir las CACs a partir de la interpretación de las imágenes de Google Earth, con respecto a su localización geográfica, tipo de hábitat, ecosistemas asociados, infraestructuras portuarias próximas y su relación con otros núcleos urbanos.

c. Georreferenciar todas las CACs en un sistema de información geográfica (QGIS); analizando la relación entre las CACs y Ios ecosistemas costero marinos obtenidos desde los mapas de UNEP-WCMC.

d. Clasificar las CACs según su tamaño. Para poder comparar el presente estudio con otras investigaciones, se tomaron los criterios de tamaño de UN-DESA (United Nations- Department of Economic and Social Affairs):

- Ciudades pequeñas (100.000 y 500.000 ${\text { habitantes })^{4}}^{4}$

- Ciudades medianas (500.000 y 1.000 .000 habitantes)

- Ciudades grandes (1.000.000 y 5.000.000 habitantes)

- Ciudades muy grandes (5.000.000 y 10.000.000 habitantes)

- Megaciudades (más de 10.000.000 habitantes)

- Cuantificar el grado de ocupación del territorio de las ciudades y aglomeraciones urbanas, tanto costeras como del interior a partir de los valores medios de ocupación de una ciudad en ALC.

- Identificar las actividades económicas asociadas al desarrollo urbano en ALC, así como las presiones que ejercen estas a los ecosistemas costero marinos.

\footnotetext{
4 En determinados resultados se obtiene información de entidades urbanas menores (EUM) a 100.000 habitantes. CIESIN, 2011.
} 


\section{Población y poblamiento urbano en las costas de ALC}

Las características básicas del poblamiento urbano se pueden definir a partir de la evolución que ha sufrido el número de ciudades y su población. De esta forma, se analiza el crecimiento de las ciudades con más de 100.000 habitantes y la población asociada para el periodo comprendido entre 1945 y 2014. A continuación, y con los criterios antes descritos, se comparan aquellas ciudades y aglomeraciones costeras (CACs) de ALC con respecto a los datos mundiales.

Los resultados de la investigación muestran que la región considerada costera en este trabajo, ha multiplicado el número de sus CACs por diez durante el periodo analizado (de 42 a 420). Esto supone un aumento de la población de 20 a casi 180 millones de personas que habitan en ciudades consolidadas a menos de $100 \mathrm{~km}$ de la costa. Al compararlo con el proceso mundial, el número de CACs en el mundo apenas ha crecido 4,5 veces para el mismo periodo, pasando en este caso de 472 a 2.129. Por tanto, el peso de las CACs en ALC con respecto al total mundial aumenta del 9 al 20\% entre 1945 y 2014 (Cuadro N ${ }^{\circ}$ 1). La importancia del crecimiento urbano de ALC en el panorama mundial se manifiesta de manera consistente en estos resultados. El análisis de la población muestra resultados no tan contundentes pero igualmente expresivos al de las ciudades. El porcentaje con respecto al total mundial aumenta del 9 al $12 \%$ en las últimas siete décadas. La diferencia tan significativa entre el espectacular aumento porcentual de las CACs y las de la población urbana de ALC con respecto a los mismos indicadores mundiales se explica por el mayor tamaño de las ciudades latinoamericanas. La relación entre las ciudades interiores y las CACs de ALC, indica una mayor cantidad de la población en los primeros $100 \mathrm{~km}$ desde la costa, que en el resto del continente. Esta relación se mantiene desde 1945, aunque la diferencia entre las ciudades interiores y las CACs es cada vez menor.

La distancia de $100 \mathrm{~km}$ que se utiliza como referencia para delimitar el litoral, se toma de trabajos de escala mundial (Small \& Nicholls, 2003). Sin embargo, este criterio puede resultar inadecuado para estudios de mayor detalle. Por ello, se realiza una diferenciación dentro de las CACs, en la que se incluyen las "ciudades de borde costero". Estas son ciudades que se extienden desde la línea de costa o que están físicamente unidas a otra ciudad que cumple este requisito. Esta definición de ciudad de borde costero se utiliza en trabajos de escala más detallada en los que se definen las áreas urbanas dentro del sistema socioecológico litoral (Barragán \& de Andrés, 2016). En tal sentido, de las 420 CACs de ALC, 173 se consideran ciudades de borde costero, decir el $41 \%$ de las CACs está ocupando la primera franja de costa. En ellas, existe una población de 90 millones de personas.

Cuadro $\mathrm{N}^{\mathrm{o}} 1$

Evolución de CACs y población urbana (x1.000) en ALC y proporción con respecto al mundo

\begin{tabular}{|r|r|r|r|r|r|r|}
\hline Década & \multicolumn{1}{|c|}{$\begin{array}{c}\text { Ciudades } \\
\text { Interiores }\end{array}$} & \multicolumn{1}{c|}{ CACs } & \multicolumn{1}{c|}{$\begin{array}{c}\text { Porcentaje de } \\
\text { CACs respecto } \\
\text { mundo }\end{array}$} & $\begin{array}{c}\text { Población } \\
\text { en ciudades } \\
\text { interiores }\end{array}$ & $\begin{array}{c}\text { Población en } \\
\text { CACs }\end{array}$ & $\begin{array}{c}\text { Porcentaje de } \\
\text { población res- } \\
\text { pecto mundo }\end{array}$ \\
\hline $1945-1954$ & 21 & 42 & 8,90 & 7.072 & 20.487 & 9,16 \\
\hline $1955-1964$ & 44 & 74 & 10,54 & 14.341 & 33.148 & 10,14 \\
\hline $1965-1974$ & 87 & 122 & 12,62 & 32.426 & 53.474 & 11,06 \\
\hline $1975-1984$ & 127 & 163 & 12,99 & 48.762 & 81.169 & 12,61 \\
\hline $1985-1994$ & 176 & 247 & 15,93 & 73.180 & 111.138 & 13,24 \\
\hline $1995-2004$ & 269 & 358 & 18,13 & 108.137 & 151.990 & 13,34 \\
\hline $2005-2014$ & 344 & 420 & 19,73 & 137.619 & 179.828 & 12,38 \\
\hline
\end{tabular}

Fuente: Elaboración propia. 
El estudio de las CACs según su tamaño muestra que las ciudades pequeñas han pasado de 34 a 356 entre 1945 y 2014. Esto supone el $85 \%$ del total de las CACs, frente al $70 \%$ que presentan los resultados mundiales. La población asociada a CACs pequeñas en ALC supone el $40 \%$ de la población urbana costera (Figura $\mathrm{N}^{\circ} 1$ ), mientras que en el mundo representa tan solo el 22\% (Figura $\mathrm{N}^{\circ} 2$ ). Algunos autores (Klaufus, 2010: 126) afirman que el $40 \%$ de la población de ALC vive en ciudades con menos de un millón de habitantes. Por otra parte, estudios de la Comisión Económica para América Latina y el Caribe (CEPAL) ponen de manifiesto el crecimiento demográfico de las ciudades entre 50.000 y un millón de habitantes, afirmando que son estas las que tienen un mayor dinamismo en relación al resto de sistemas urbanos (Jordan y Simioni, 1998: 60). El crecimiento de las ciu- dades pequeñas es especialmente importante en los últimos años (Bárcena, 2001; Beltrão, 2015; UN-Habitat, 2012). Estas ciudades de menor tamaño se desarrollan próximas a las grandes urbes, generando áreas urbanas mayores a partir de fenómenos de conurbación y metropolización (UN-Habitat, 2000). Las ciudades medianas y grandes en ALC suponen, respectivamente, un $9 \%$ y un $1 \%$ del total de CACs, porcentajes más bajos que los de la media mundial, donde alcanzan un $15 \%$ y un $13 \%$ respectivamente. En cuanto a las megaciudades, de las 15 costeras del mundo, solo una se encuentra en ALC (São Paulo). Pero en realidad este resultado admite matices. De hecho, si se tuvieran en cuenta factores de proximidad entre diferentes CACs, las áreas metropolitanas de Buenos Aires y Río de Janeiro, por ejemplo, superarían los diez millones de habitantes (UN-DESA, 2014: 26).

Figura $\mathrm{N}^{\circ} 1$

Evolución de la población en CACs de ALC clasificadas por tamaño. Periodo 1945-2014

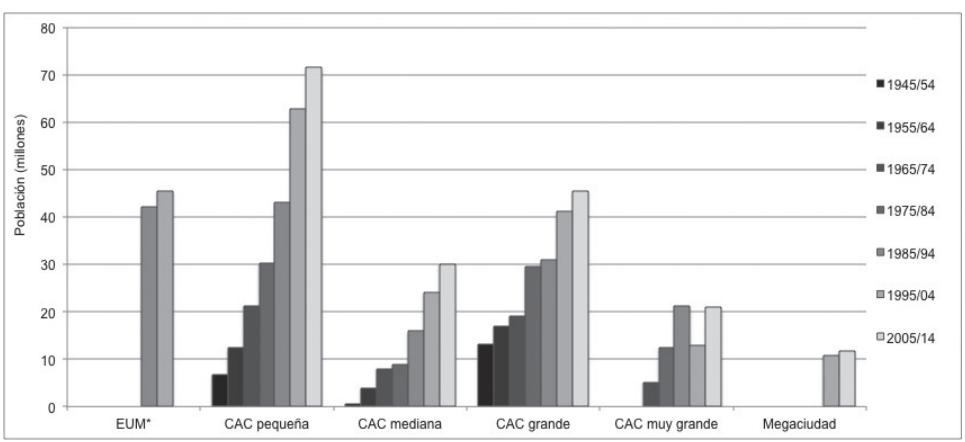

* EUM (Entidades Urbanas Menores). Datos disponibles para 1990 y 2000 (CIESIN, 2011). Fuente: Elaboración propia.

Figura $\mathrm{N}^{\circ} 2$

Evolución de la población en CACs del mundo clasificadas por tamaño. Periodo 1945-2012

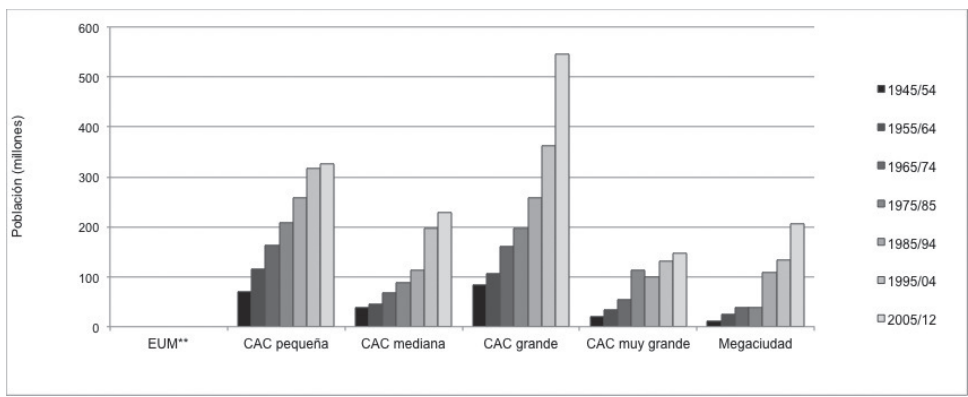

**EUM (Entidades Urbanas Menores). Sin información.

Fuente: Elaboración propia 
Comparando las Figuras $\mathrm{N}^{0} 1$ y $\mathrm{N}^{\circ} 2$ se observa que el patrón evolutivo de América Latina y Caribe es diferente del seguido por el conjunto de CACs del mundo. Mientras en este existe una concentración de la población en las grandes ciudades y megaciudades, en ALC es más destacado el desarrollo de las ciudades pequeñas, sobre todo en los últimos años. Las principales diferencias entre las dos escalas geográficas se resumen en el Cuadro $\mathrm{N}^{\circ} 2$.

Cuadro $\mathrm{N}^{\circ} 2$

Perfil comparativo entre las CACs de América Latina y Caribe y del mundo

\begin{tabular}{|c|c|}
\hline Mundo & América Latina y Caribe \\
\hline $\begin{array}{l}\text { El número total de CACs ha pasado de } 472 \text { a } \\
2.129 \text { en el período estudiado }(x 4,5)\end{array}$ & $\begin{array}{l}\text { El número total de CACs ha pasado de } 42 \text { a } 420 \\
\text { en el período estudiado (x10) }\end{array}$ \\
\hline $\begin{array}{l}\text { La población en CACs ha pasado de } 223 \text { mi- } \\
\text { Ilones a } 1.452 \text { millones de personas }(\times 6,5)\end{array}$ & $\begin{array}{l}\text { La población en CACs ha pasado de } 20 \text { millones } \\
\text { a } 180 \text { millones de personas (x9) }\end{array}$ \\
\hline $\begin{array}{l}\text { Las CACs pequeñas se han multiplicado por } \\
4 \text { en los últimos } 70 \text { años }\end{array}$ & $\begin{array}{l}\text { Las CACs pequeñas se han multiplicado por } 10 \\
\text { en el mismo periodo }\end{array}$ \\
\hline $\begin{array}{l}\text { La población costera urbana vive mayorita- } \\
\text { riamente en CACs grandes; entre } 1 \text { y } 5 \text { mi- } \\
\text { llones de habitantes }(38 \%)\end{array}$ & $\begin{array}{l}\text { La población costera urbana vive mayoritaria- } \\
\text { mente en ciudades pequeñas; entre } 100.000 \text { y } \\
500.000 \text { habitantes }(40 \%)\end{array}$ \\
\hline Existen 15 megaciudades en la zona costera. & $\begin{array}{l}\text { São Paulo es la única megaciudad costera en } \\
\text { ALC. (Buenos Aires y Río de Janeiro superarían } \\
\text { los } 10 \text { millones si se tiene en cuenta el área me- } \\
\text { tropolitana (UN-DESA, 2014: 26)) }\end{array}$ \\
\hline $\begin{array}{r}\text { La población costera actual en CACs pequei } \\
\text { años en las CACs pe }\end{array}$ & $\begin{array}{l}\text { s de ALC es la misma que la que había hace } 70 \\
\text { eñas de todo el mundo. }\end{array}$ \\
\hline
\end{tabular}

Fuente: Elaboración propia.

\section{La ocupación del territorio en ALC}

El fenómeno de la expansión y crecimiento urbanos en las áreas litorales tiene una especial importancia en cuanto a la ocupación del territorio se refiere. Se trata de una franja que supone entre el 4\% (Cohen \& Small, 1998) y el $15 \%$ (UNEP, 2006) de la superficie terrestre. Además, en ALC alberga ecosistemas costero marinos de gran importancia como manglares y arrecifes de coral. Por ello, la ocupación del suelo y el cambio de usos por la continua urbanización del litoral, constituye un tema de especial trascendencia (Barragan, 2014).

Con objeto de comprobar si coexisten dos modelos diferentes de poblamiento en ALC, se procede a analizar la ocupación del territorio por parte de las CACs y se compara con el de las ciudades del interior. Para ello se agruparon las CACs a partir de las tres grandes fachadas costeras que, a escala mundial, se identifican para ALC: la atlántica, la pacífica y la fachada del Caribe (CIESIN, 2011). El número medio de ciudades por cada 10.000 $\mathrm{km}^{2}$ de litoral en ALC pasa de 0,12 a 1,08 durante el período estudiado, mientras que en el interior lo hace de 0,01 a 0,1 (Figura $N^{\circ} 3$ ); o lo que es lo mismo, actualmente en el litoral, encontramos de media una ciudad cada $9.000 \mathrm{~km}^{2}$, mientras que en el interior ocurre cada $96.000 \mathrm{~km}^{2}$. La ocupación actual del litoral por CACs es especialmente elevada en la fachada caribeña. En este ámbito las CACs ocupan 2,6 km² por cada $100 \mathrm{~km}^{2}$ de lito- 
ral. Mientras que la ocupación media de las CACs en ALC es de tan solo la mitad $\left(1,3 \mathrm{~km}^{2}\right.$ por cada $100 \mathrm{~km}^{2}$ ). En la Figura $N^{\circ} 4$ están representadas todas las ciudades del Caribe, reflejándose la importancia de la ocupación urbana sobre el litoral caribeño. En cuanto a la densidad de población urbana que se encuentra en el litoral, se obtiene que en las tres subregiones, la densidad de población ha pasado de menos de 10 habitantes por $\mathrm{km}^{2}$ a 30 habitantes por $\mathrm{km}^{2}$ en el Atlántico sur y el Pacífico sur, y a más de 50 habitantes por $\mathrm{km}^{2}$ en el Mar Caribe. Además, en el periodo 2005-2014 destacan Puerto Rico y Brasil al presentar la mayor densidad de población urbana en la zona costera. En ambos se contabilizan más de 100 habitantes en ciudades por kilómetro cuadrado de litoral. Mientras que, por ejemplo, la densidad en el interior de Brasil es tan solo de 5,4 habitantes por kilómetro cuadrado.

\section{Figura $\mathrm{N}^{\circ} 3$}

Ocupación del suelo por ciudades en diferentes subregiones de ALC. Análisis en tres periodos de estudio. Comparación entre el litoral (claro) y el interior (oscuro)

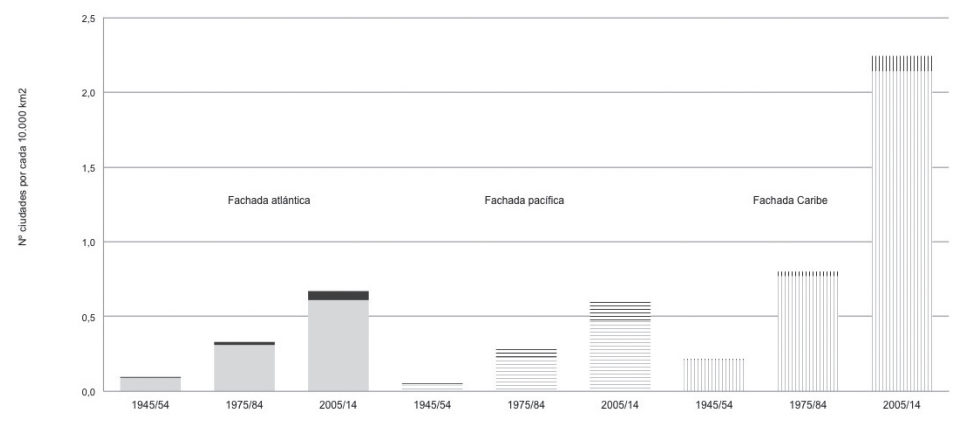

Fuente: Elaboración propia.

\section{Figura $N^{\circ} 4$}

Ciudades mayores a 100.000 habitantes y entidades urbanas menores en el Caribe y el Pacífico centroamericano. Los círculos de color gris claro representan ciudades interiores y círculos en color negro corresponden a ciudades litorales

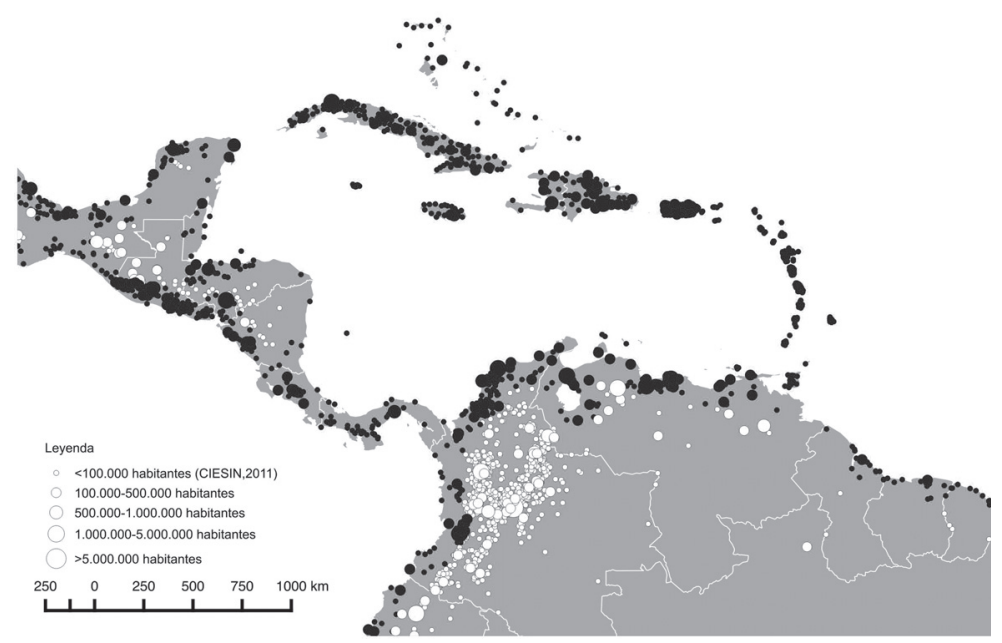

Fuente: Elaboración propia. 
En las zonas costeras de ALC, la aparición de metrópolis o conurbaciones son fenómenos bastante usuales en las que se presenta la urbanización (McGranahan et al., 2004). Uno de los mecanismos por los que se producen procesos de conurbación, es a partir de la unión de entidades urbanas menores a las existentes CACs. Para estudiar este proceso, se han incorporado a las bases de datos iniciales (CACs mayores de 100.000 habitantes) las EUM menores de 100.000 habitantes. Esta última información procede, para 1990 y 2000, de los informes elaborados por el CIESIN (Centre for International Earth Science Information Network). El método de trabajo es sencillo: se vincula en un SIG la capa de información referida a las EUM, con la ela- borada para nuestro trabajo (CACs mayores de 100.000 habitantes). El resultado permite identificar cuántas de estas últimas tienen a menos de $100 \mathrm{~km}$ otras ciudades más pequeñas. La población en CACs para ALC era de 152 millones para el periodo 1995-2004, repartida en 358 núcleos (Cuadro $N^{\circ} 3$ ). Los posibles fenómenos de conurbación se observan al contabilizar casi 39 millones de personas más que viven en EUM a menos de $100 \mathrm{~km}$. Es decir, en total superan los $190 \mathrm{mi}-$ Ilones de personas. El futuro de la ocupación del territorio a lo largo del litoral de ALC se vislumbra claramente como un medio urbano, en el que los procesos naturales estarán condicionados, en gran medida, por las actividades humanas.

\section{Cuadro $\mathrm{N}^{\circ} 3$}

Número de entidades urbanas menores próximas a CACs y la población asociada a ellos. Población total en las CACs y las EUM próximas

\begin{tabular}{|c|r|r|r|r|r|}
\hline Periodo & CACs & $\begin{array}{c}\text { Población en } \\
\text { CACs }(x 1.000)\end{array}$ & $\begin{array}{c}\text { EUM (CIESIN, } \\
\text { 2011) }\end{array}$ & $\begin{array}{c}\text { Población en } \\
\text { EUM (x1.000) } \\
\text { (CIESIN, 2011) }\end{array}$ & $\begin{array}{r}\text { Población total } \\
(\times 1.000)\end{array}$ \\
\hline $1985-1994$ & 247 & 111.138 & 1.484 & 35.670 & 146.808 \\
$1995-2004$ & 358 & 151.990 & 1.599 & 38.831 & 190.821 \\
\hline
\end{tabular}

Fuente: Elaboración propia en base a datos de CIESIN, 2011.

A pesar de que la mayoría de las CACs $(88 \%)$ poseen asentamientos menores en su área de influencia, este no es el único mecanismo por el que se originan los procesos conurbatorios. La existencia de CACs en expansión, cercanas unas de otras, puede originar la unión de las mismas, como de hecho, sucede en diferentes ciudades en el litoral de ALC. Para cuantificar este proceso, se analizan aquellas CACs que tienen a menos de 50 $\mathrm{km}$ otra CAC. El resultado obtenido muestra que actualmente, 264 ciudades litorales en ALC tienen al menos otra CAC próxima. Esto supone que el $64 \%$ de las CACs son susceptibles de sufrir procesos conurbatorios. En la Figura $N^{\circ} 5$ se representan todas las ciudades mayores a 100.000 habitantes, observándose la importancia de la concentración urbana sobre el litoral. 
Figura $\mathrm{N}^{\circ} 5$

Ciudades mayores a 100.000 habitantes en ALC. Los círculos de color gris claro representan ciudades interiores y círculos en color negro corresponden a ciudades litorales

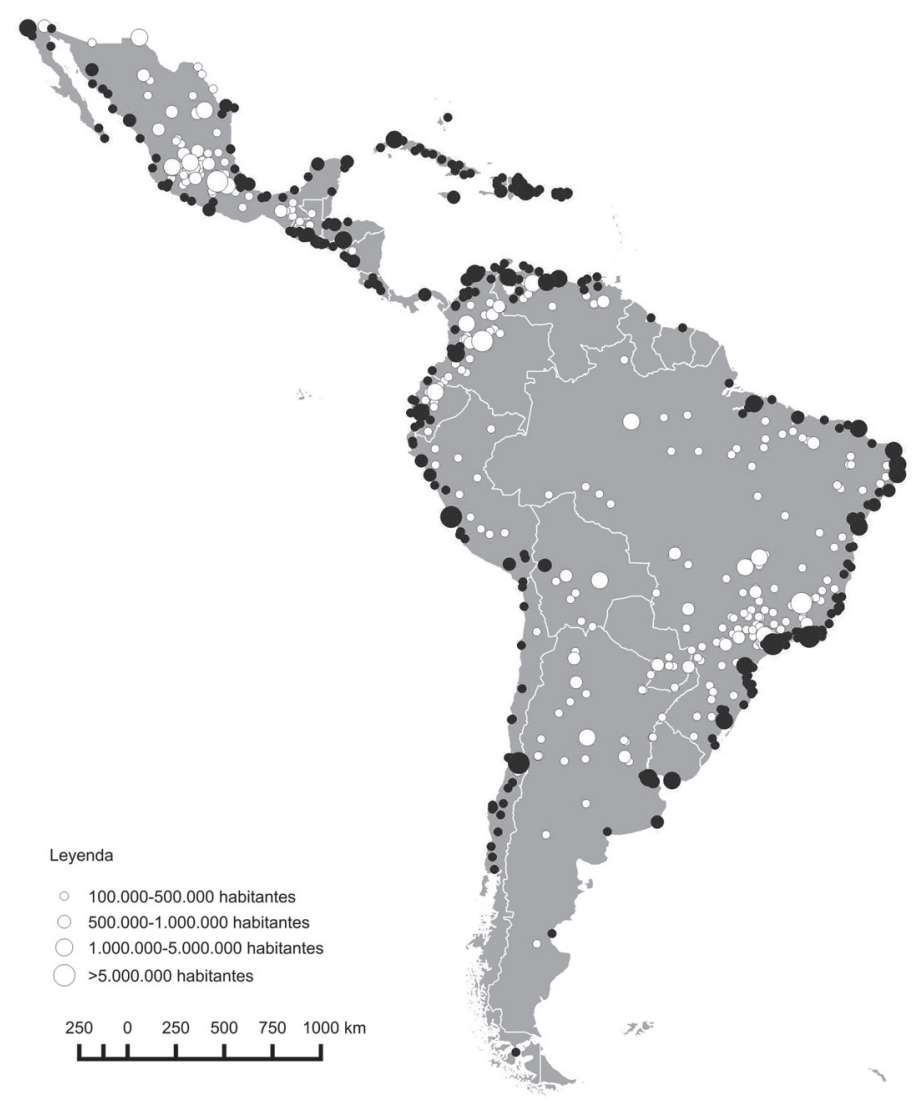

Fuente: Elaboración propia

\section{Las ciudades costeras en el modelo de socioecológico de ALC}

\section{Bahías y lagunas costeras}

Las bahías, entendidas como cuerpos de agua abrigados, donde suelen desarrollarse actividades ligadas al transporte marítimo, han sido lugares privilegiados para los asentamientos humanos. Estas unidades albergan ecosistemas que proporcionan numerosos servicios al ser humano tanto de aprovisionamiento, como culturales y de regulación
(Barragan, 2014). Los resultados de la investigación son bastante elocuentes. Bahías y lagunas costeras han multiplicado por $10 \mathrm{su}$ desarrollo urbano entre el final de la Segunda Guerra Mundial y la actualidad: mientras al principio del período había apenas 18 CACs hoy días Ilegan a 179. Esto explica que más de 88 millones de personas se asienten en bahías o lagunas costeras con núcleos urbanos consolidados. El peso relativo de su población con respecto al total de las que viven en CACs también ha crecido, pasando del $45 \%$ al $49 \%$. Por tanto, se puede afirmar que casi la mitad de la población de las CACs de ALC se concentran en este tipo de unidades fisiográficas. 
El tamaño de ciudad que se desarrolla en el seno de las bahías también ha evolucionado. Hasta 1995 eran las ciudades grandes (entre 1 y 5 millones) las que más población albergaban, pero el gran aumento de las ciudades pequeñas próximas en las últimas décadas, ha originado que más de 30 millones de personas se encuentren viviendo en estas CACs (Cuadro $N^{\circ} 4$ ). Este proceso se debe principalmente al desarrollo económico de las ciudades asociadas, por la existencia de puertos y actividades turísticas. El crecimiento de ciudades pequeñas en torno a las grandes CACs, implica un claro proceso de nueva ocupación o intensificación de la ocupación anterior en unidades fisiográficas que albergan valiosos ecosistemas costero marinos. Estos ecosistemas en muchas ocasiones se encuentran degradados por actividades urbanas, como ocurre, por ejemplo, en las bahías de
Cuba que son afectadas por vertidos procedentes del alcantarillado urbano sin depurar (Cabrera et al., 2010). Las de La Habana, Matanzas, Cienfuegos o Santiago de Cuba son solo algunos ejemplos. Otro caso se presenta en la bahía de Guanabara, que acoge a la región urbana de Río de Janeiro y sobre la que se vierten diariamente 50 toneladas de metales pesados (Scherer et al., 2010).

La evolución que ha sufrido la ocupación del territorio en torno a las bahías, muestra que actualmente hay $25.000 \mathrm{~km}^{2}$ ocupados por CACs. Lo que conlleva un importante cambio en los usos del suelo de estas unidades fisiográficas tan susceptibles a la contaminación. La consolidación de sus núcleos urbanos provoca un deterioro de sus ecosistemas costero marinos, además de una fragmentación de los hábitats naturales.

\section{Cuadro $\mathrm{N}^{\circ} 4$}

Evolución de CACs y población urbana próximas a bahías y lagunas costeras

\begin{tabular}{|c|r|r|r|r|}
\hline Periodo & \multicolumn{1}{|c|}{ CACs } & \multicolumn{1}{c|}{$\begin{array}{c}\text { Porcentaje } \\
\text { CACs }\end{array}$} & \multicolumn{1}{|c|}{$\begin{array}{c}\text { Población } \\
(\times 1.000)\end{array}$} & $\begin{array}{c}\text { Porcentaje } \\
\text { Población }\end{array}$ \\
\hline $1945-1954$ & 18 & 42,86 & 9.147 & 44,65 \\
\hline $1955-1964$ & 36 & 48,65 & 16.040 & 48,39 \\
\hline $1965-1974$ & 60 & 49,18 & 26.904 & 50,31 \\
\hline $1975-1984$ & 75 & 46,01 & 39.040 & 48,10 \\
\hline $1985-1994$ & 107 & 43,32 & 54.094 & 48,67 \\
\hline $1995-2004$ & 157 & 43,85 & 73.960 & 48,66 \\
\hline $2005-2014$ & 176 & 41,90 & 88.165 & 49,03 \\
\hline
\end{tabular}

Fuente: Elaboración propia.

\section{Deltas y estuarios}

La mayoría de los grandes ríos de ALC desembocan en la fachada atlántica, aunque podemos destacar en México el delta del Colorado que se encuentra en el golfo de California. Estas desembocaduras, en forma de deltas o estuarios, suelen albergar ecosistemas que ofrecen servicios extraordinariamente valiosos a la sociedad. Además, casi siempre son atractivos para el desarrollo de áreas urbanas. Solo basta recordar algunos casos como el Río de la Plata, que acoge a una importante cantidad de la población ur- bana de Argentina y Uruguay (Buenos Aires, Montevideo) (Barragán et al., 2003; EcoPlata, 1999; Pérez-Cayeiro \& Chica-Ruiz, 2015), o el estuario de Bahía Blanca (Argentina) que sufre una rápida expansión urbana en sus márgenes como consecuencia del desarrollo portuario y la instalación de grandes industrias (Dadon, 2010; Kopprio et al., 2015).

En la actualidad, hay 174 CACs en ALC próximas a deltas o estuarios (Cuadro $\mathrm{N}^{\circ} 5$ ), esto supone el $42 \%$ de la población urbana costera. Del análisis de las ciudades y la población, según el tamaño de ciudad, se obtie- 
ne que las CACs pequeñas son las que tienen una mayor parte de la población. Estas CACs ascienden a 146 en el periodo 2005-2014, lo que supone un $83 \%$ del total. Por tanto, se puede afirmar que las ciudades pequeñas son las que prevalecen en los entornos de estos ambientes. Ello puede interpretarse como una amplia red de ciudades, cuyo crecimiento implica, en un futuro próximo, la colonización de nuevas áreas costeras bien conservadas. Por otra parte, el análisis de la ocupación del territorio, muestra la elevada magnitud en el cambio de usos del suelo en deltas y estuarios, ya que en la actualidad existen 24.500 $\mathrm{km}^{2}$ ocupados por núcleos urbanos consolidados. Por tanto, la presión que ejercen las CACs sobre las desembocaduras es cada vez mayor; originando problemas de subsidencia, inundaciones y aumento de riesgos frente al cambio climático (Palmer et al., 2008: 83; Van Vuuren et al., 2011: 576).

Además de la problemática futura, el impacto actual del aumento de población sobre estos ecosistemas reside tanto en la pérdida del propio hábitat, como en la degradación que provoca la contaminación del mismo. Por ejemplo, la ciudad de Guayaquil en Ecuador ha pasado de 250 mil habitantes en 1950 a más de 2,2 millones actualmente. Este crecimiento se ha realizado en torno al estuario Salado del río Guayas. Por una parte, ha provocado la desaparición de bosques de manglar que se encontraban en el estuario $y$, por otra, a la contaminación del propio estuario por las industrias y los usos domésticos (Delgado, 2013: 520).

Cuadro $\mathrm{N}^{\circ} 5$

Evolución de CACs y población urbana próximas a deltas y estuarios

\begin{tabular}{|r|r|r|r|r|}
\hline \multicolumn{1}{|c|}{ Periodo } & CACs & \multicolumn{1}{c|}{$\begin{array}{c}\text { Porcentaje } \\
\text { CACs }\end{array}$} & Población $(x 1.000)$ & $\begin{array}{c}\text { Porcentaje } \\
\text { Población }\end{array}$ \\
\hline $1945-1954$ & 22 & 52,38 & 9.850 & 48,08 \\
$1955-1964$ & 37 & 50,00 & 14.842 & 44,77 \\
$1965-1974$ & 60 & 49,18 & 23.421 & 43,80 \\
$1975-1984$ & 72 & 44,17 & 32.694 & 40,28 \\
$1985-1994$ & 105 & 42,51 & 46.134 & 41,51 \\
$1995-2004$ & 153 & 42,74 & 60.919 & 40,08 \\
$2005-2014$ & 174 & 41,43 & 74.374 & 41,36 \\
\hline
\end{tabular}

Fuente: Elaboración propia.

\section{Arrecifes de coral}

Son ecosistemas costeros que proporcionan considerables servicios que inciden positivamente en el bienestar humano (Grimsditch \& Salm, 2006). Estos ecosistemas originan importantes hábitats costeros. Y ALC alberga la segunda barrera de arrecifes de coral más grande del mundo, tras la australiana (Burke \& Maidens, 2005; Jackson et al., 2014). Algunos países como México (Tovilla et al., 2010) o Cuba (Cabrera et al., 2010) tienen en las áreas arrecifales que bordean su litoral importantes ecosistemas que abastecen de numerosos servicios a la población residente o visitante.
El número de CACs que se encuentra a menos de $100 \mathrm{~km}$ de un arrecife de coral en ALC se multiplica por 10 durante el período estudiado (de 13 a 136) (Cuadro $N^{\circ}$ 6). Pero más impresionante es lo que ocurre con la población: los habitantes de las CACs asociadas pasan de 4 a más de 52 millones de habitantes. En lo relativo a la proporción entre la población asociada a áreas arrecifales y la población urbana total, esta ha pasado del 22 al $29 \%$ en las últimas siete décadas. Se puede afirmar, por tanto, que buena parte de la población urbana costera de la América tropical se está asentando cerca de estos ecosistemas. Por otra parte, conviene resaltar que los países insulares del Caribe, Panamá y Costa Rica 
tienen todas sus CACs a menos de $100 \mathrm{~km}$ de arrecifes de coral; y Venezuela y Colombia más de 50\%. Estos resultados muestran la prioridad que debería orientar las políticas nacionales en cuanto a determinados equipamientos urbanos y ecosistemas costeros marinos. Los resultados de la investigación muestran que el área ocupada por CACs localizadas cerca de arrecifes de coral suponen $20.000 \mathrm{~km}^{2}$ actualmente. Los impactos asociados al desarrollo urbano, se relacionan tanto con el cambio de usos del suelo, como con el aumento de la presión demográfica. La construcción de núcleos urbanos sobre la franja costera provoca una contaminación por vertidos urbanos no depurados que afecta a los arrecifes. Ejemplos de este proceso se observan en la costa Caribe de Panamá, ya que a causa de los vertidos aumenta la turbidez de las aguas, causando así su degradación (Guzmán, 2003: 260). Los arrecifes de Puerto Rico, por su parte, son unos de los más afectados del Caribe, debido principalmente al desarrollo urbano, turístico e industrial (García et al., 2003; Seguinot, 1996). Estos ejemplos muestran las implicaciones del proceso urbanizador del litoral sobre ecosistemas costero marinos tan vulnerables. En 2005 el área estimada por el Instituto de Recursos Mundiales de arrecifes coralinos en el Caribe era de $25.960 \mathrm{~km}^{2}$, donde un tercio está amenazado por las presiones asociadas al desarrollo costero, incluyendo las descargas de aguas residuales, drenaje urbano y construcción (Barragán, 2012: 33).

\section{Cuadro $\mathrm{N}^{\circ} 6$}

Evolución de CACs y población urbana a menos de 100 km de arrecifes de coral

\begin{tabular}{|r|r|r|r|r|}
\hline \multicolumn{1}{l|}{ Periodo } & \multicolumn{1}{c|}{ CACs } & \multicolumn{1}{c|}{ \% CACs } & \multicolumn{1}{c|}{$\begin{array}{c}\text { Población } \\
(x 1.000)\end{array}$} & \multicolumn{1}{c|}{ \% Población } \\
\hline $1945-1954$ & 13 & 31 & 4.460 & 22 \\
\hline $1955-1964$ & 23 & 31 & 8.676 & 26 \\
\hline $1965-1974$ & 37 & 30 & 13.575 & 28 \\
\hline $1975-1984$ & 51 & 31 & 22.369 & 26 \\
\hline $1985-1994$ & 75 & 30 & 29.203 & 27 \\
\hline $1995-2004$ & 115 & 32 & 41.513 & 29 \\
\hline $2005-2014$ & 136 & 32 & 52.797 & \\
\hline
\end{tabular}

Fuente: Elaboración propia.

\section{Manglares}

Los bosques de manglar son propios de las zonas más cálidas de ALC, representando hábitats importantes en la región. Tal es el caso de los estuarios del litoral Pacífico de Colombia y Panamá que se caracterizan por albergar extensos bosques de manglar (Arenas \& Garcés, 2010; Caviedes et al., 2014). Las alteraciones de estos ecosistemas para la urbanización, entre otras prácticas, ha provocado la destrucción y la fragmentación de hábitats costeros, así como la pérdida de la biodiversidad asociada. También los manglares estuarinos pueden degradarse debido a las alteraciones de los balances sedimentarios producidas aguas arriba (a veces mucho más allá de los $100 \mathrm{~km}$ elegidos como distancia de referencia).

El porcentaje de ciudades que se asientan próximas a manglares con respecto al total de CACs crece del $62 \%$ al $80 \%$ en los últimos 70 años (Cuadro $N^{\circ} 7$ ). Si la tendencia con respecto a los arrecifes de coral era creciente, la evolución que se observa en relación a los manglares es aún mayor. La población urbana próxima crece de 11 a más de 133 millones entre 1945 y 2014, y supone un aumento del 54 al $74 \%$ con respecto a toda la población urbana costera. Estos resultados de la investigación reflejan una tendencia clara: la 
población está creciendo en ciudades próximas a áreas de manglar. Este modelo de organización territorial se explica por la estrecha relación que se establece entre núcleos de poblamiento históricos, lugares elegidos por las antiguas metrópolis para consolidar la ocupación y explotación durante la etapa colonial, localización de los principales puertos y focos de la economía postcolonial, etc. (Giri et al., 2011; UN-Habitat, 2012; Valiela et al., 2001). Pero, también, y ya en el siglo $\mathrm{XX}$, porque estos espacios intermareales suelen coincidir con áreas públicas, donde la pobreza se manifiesta en forma de ocupación urbana, informal y desordenada. A lo largo de las últimas décadas, las diferentes iniciativas gubernamentales han tendido a facilitar la consolidación de estos asentamientos urbanos con la construcción de infraestructuras y equipamientos públicos.

Atendiendo al tamaño de las CACs, el $86 \%$ tienen una población entre 100,000 y 500,000 habitantes. Ello implica una base muy sólida para el futuro crecimiento del sistema urbano. Por tanto, es posible que la presión sobre estos ecosistemas tan valiosos siga intensificándose en las próximas déca- das. Además, los resultados por países muestran que, exceptuando aquellos del cono sur, todos los países costeros de ALC tienen la mayoría de sus CACs no muy lejos de bosques de manglar. Por otra parte, el estudio de la ocupación de las CACs muestra que en la actualidad hay más de 47.000 kilómetros cuadrados próximos a manglares, que están ocupados por núcleos urbanos mayores a 100.000 habitantes.

Los informes realizados por la FAO indican que, entre 1980 y 2005, los manglares en ALC han pasado de ocupar 50.000 a 40.000 $\mathrm{km}^{2}$ (FAO, 2007). Es muy significativo, por tanto, que se constate una superficie urbana ejerciendo presión sobre los manglares, mayor al área que ocupan dichos ecosistemas. Es importante destacar que la presión de la expansión urbana no requiere que dichos núcleos urbanos estén localizados en las inmediaciones de los manglares. Buena parte del deterioro de estos ecosistemas se explica por el inadecuado desarrollo urbano y en general uso del suelo incluso a cientos de kilómetros de distancia, aguas arriba en la misma cuenca hidrográfica.

Cuadro $\mathrm{N}^{\circ} 7$

Evolución de CACs y población urbana a menos de 100 km de manglares

\begin{tabular}{|r|r|r|r|r|}
\hline \multicolumn{1}{|c|}{ Periodo } & CACs & $\begin{array}{c}\text { Porcentaje } \\
\text { CACs }\end{array}$ & $\begin{array}{c}\text { Población }(x \\
1.000)\end{array}$ & $\begin{array}{c}\text { Porcentaje de } \\
\text { Población }\end{array}$ \\
\hline $1945-1954$ & 26 & 62 & 11.052 & 54 \\
$1955-1964$ & 52 & 70 & 21.097 & 64 \\
$1965-1974$ & 91 & 75 & 36.413 & 68 \\
$1975-1984$ & 122 & 75 & 56.745 & 70 \\
$1985-1994$ & 189 & 77 & 81.631 & 73 \\
$1995-2004$ & 287 & 80 & 116.301 & 76 \\
$2005-2014$ & 334 & 80 & 133.557 & 74 \\
\hline
\end{tabular}

Fuente: Elaboración propia

\section{Principales actividades económicas en el litoral de ALC}

El patrón de desarrollo de la región provoca un aumento en las presiones ejercidas sobre el litoral. Por tanto, se precisan mecanismos de gestión integrada para hacer frente a los problemas ecológicos y socioeconómicos. La Red Iberoamericana de Manejo Costero Integrado, Ibermar, realizó un diagnóstico de las zonas costeras de los 13 países miembros. De este informe se extraen las principales actividades económicas relacionadas con el litoral en ALC. Entre ellas, destacan el turismo, las actividades portuarias y las industriales como los principales sectores económicos, 
que además se relacionan con la expansión urbana en el litoral (Arenas, 2012).

\section{Turismo}

Los datos de la Organización Mundial de Turismo muestran que, mientras el turismo global presenta un incremento en 2013 del $4,7 \%$ con respecto a 2012, la región de ALC crece un 7,4\% (UNWTO, 2014). Estos datos ponen de manifiesto la importancia que tiene dicho conjunto de actividades del sector terciario en la región. Según la información del Banco Interamericano de Desarrollo, el 6\% del empleo total de ALC se debe al turismo, lo que equivale a uno de cada 16 empleos en 2009. Supone, además, el $40 \%$ del PIB de los países del Caribe (UN-Habitat, 2012: 80). Todos estos indicadores muestran la trascendencia que supone el desarrollo turístico para la economía de la población de ALC. La planificación de una ciudad especializada en el turismo no ocurre de la misma forma que el resto de las ciudades (Mullins, 1991). Tal es el caso, por ejemplo de la ciudad de Varadero en Cuba cuyo crecimiento urbano se debe principalmente a la prosperidad del negocio turístico (Gonzalez et al., 2013). Otros ejemplos se observan en ciudades como Mar del Plata (Argentina), San José (Costa Rica), Florianópolis (Brasil) o Valparaíso- Viña del Mar (Chile), todas ellas ciudades litorales cuyo desarrollo urbano está asociado en buena parte con el sector turístico.

La rápida expansión del turismo en las zonas costeras de ALC y la proliferación de complejos turísticos sin planificación, conlleva la pérdida o degradación de ecosistemas como manglares o lagunas costeras, originando, además, una pérdida de la diversidad cultural de la región (UNEP, 2006) y el incremento de riesgos en ámbitos de sustrato blando (Monti y Escofet, 2008; Verón, 2014; Consuelo et al., 2010). Un ejemplo de considerables dimensiones lo encontramos en Cancún, una ciudad que apenas alcanzaba los 100.000 habitantes en los ochenta, tiene ahora más de 600.000. Su acelerado crecimiento se ve multiplicado con la recepción de millones de turistas cada año (UN-Habitat, 2012). Otro ejemplo se observa en la ciudad de La Habana. En los 50 se comenzó la construcción de centros urbanos complementarios a esta ciudad únicamente con una finalidad turística. A partir de 1990 se orienta hacia una estrategia turística internacional, lo que conlleva el desarrollo de ocho áreas turísticas prioritarias en los siguientes cinco años, provocando el rápido crecimiento del área urbana de la ciudad (Colantonio \& Potter, 2006).

El desarrollo turístico en ALC origina, por tanto, expansión urbana en el borde costero. Lamentablemente, en bastantes ocasiones, no es acompañado de una ordenación adecuada. Este crecimiento del turismo, aunque sigue prevaleciendo sobre las grandes ciudades, se reproduce, cada vez más, sobre ciudades medianas y pequeñas provocando que aumente la importancia de las mismas (Bárcena, 2001; CEPAL, 2003). De esta forma, el turismo, entre otras actividades, se convierte en uno de los motores que propicia el desarrollo de las pequeñas CACs en ALC al hacerlas competitivas frente a las grandes ciudades de la región.

\section{Actividades portuarias}

La decisión de construir un puerto se asocia a diferentes criterios: físicos y naturales (emplazamiento), comerciales (localización respecto a corredores de tráfico marítimo), necesidad de evacuación de materias primas (exportación de minerales o productos agrícolas), de equipamiento (como respuesta a las necesidades infraestructurales de núcleos urbanos o industriales), etc. (CEPAL, 2014; Wilmsmeier et al., 2011). Los resultados de la investigación ponen de manifiesto el elevado número de CACs próximas a puertos. Actualmente son 364 las ciudades y aglomeraciones costeras las que tienen algún tipo de infraestructuras portuarias asociadas, lo que supone el $87 \%$ de todas las CACs. En cuanto a la población, 165 millones de personas viven en estas CACs, por lo que el $91 \%$ de la población urbano costera (en ciudades mayores a 100.000 habitantes) está asociada de alguna forma a este tipo de infraestructuras.

Según los datos del CEPAL, en 2013, los diez puertos más importantes de ALC eran Colón (Panamá), Santos (Brasil), Balboa (Panamá), Manzanillo (México), Cartagena (Colombia), Callao (Perú), Buenos Aires (Argentina), Kingston (Jamaica), Guayaquil 
(Ecuador) y Freeport (Bahamas). Estos tienen ciudades asociadas en las que la actividad portuaria se entrelaza con otras propias del medio costero marino. El análisis de la evolución de las CACs próximas a los grandes puertos de ALC muestra en primer lugar que, a excepción de Freeport y Colón (que son auténticas plataformas logísticas vinculadas a facilidades portuarias), el resto tiene asociadas ciudades mayores a 100.000 habitantes. Un caso digno de estudio es el puerto de Santos, en Brasil. La densa red de infraestructuras viarias entre São Paulo y Santos hacen de este último el puerto de una de las urbes más grandes de ALC y del mundo. El tráfico comercial que genera una población urbana de casi 21 millones de personas, así como la mayor concentración industrial del país, hace que São Paulo sea altamente dependiente de las facilidades que proporciona el puerto de Santos. Las CACs asociadas a los principales puertos de ALC han seguido una tendencia similar a la del resto de ciudades litorales. Sin embargo, destaca el hecho de que las ciudades portuarias más pequeñas (las que están próximas al puerto de Manzanillo o de Kingston, por ejemplo), siguen una tendencia de mayor crecimiento en los últimos años, que las grandes regiones urbanas como São Paulo o Buenos Aires. Por tanto, las ciudades pequeñas y medianas en torno a infraestructuras portuarias tienen un potencial de crecimiento futuro mayor que otras CACs de ALC.

El crecimiento de ciudades alrededor de los principales puertos provoca grandes transformaciones sobre el litoral. Algunos de los impactos generados por la construcción de un puerto más citados son: desaparición de hábitats debido al cambio de usos del suelo, contaminación de las aguas, erosión, etc. (Barragan, 2003). Un ejemplo se observa en Bahía Málaga (Pacífico colombiano). Durante años los empresarios del Valle del Cauca apoyaron un proyecto para construir un nuevo puerto de aguas profundas. Este se situaba solo a unas pocas millas de distancia del otro gran puerto colombiano del Pacífico (Buenaventura), el cual ofrece importantes posibilidades de futuros desarrollos. Pero la iniciativa portuaria fracasó. El área fue declarada Parque Nacional Natural, entre otras razones, por su extraordinaria biodiversidad, su magnífico estado de conservación (bos- ques de manglar), y por constituir un hábitat crítico fundamental en el Hemisferio Sur para la ballena jorobada (Barragán, 2010).

\section{Industria}

Entre las principales industrias que se desarrollan en ALC relacionadas con las CACs, destacan las vinculadas a la transformación o almacenamiento de combustibles fósiles (carbón, petróleo y gas) y a los complejos químicos. Las explotaciones de petróleo en ALC comenzaron a principios del siglo XX en torno al lago Maracaibo (OilWatch, 2004). En el año 2000 en las zonas costeras de ALC había 69 explotaciones tanto de petróleo como de gas consideradas como grandes o muy grandes (Halbouty, 2000). Estos yacimientos pueden ser offshore o encontrarse en la parte terrestre del litoral. El desarrollo de la industria extractiva de gas y petróleo contribuye a explicar parte del incremento de las CACs. Así, el número de CACs que había en 1945 a menos de $100 \mathrm{~km}$ de los yacimientos actuales era solo de 6. En la actualidad esa cifra casi se ha multiplicado por veinte. También el peso relativo de la población asociada a estas ciudades ha crecido en el período estudiado: al principio significaba un $25 \%$ y en la actualidad supone un $30 \%$ de todas las personas que viven en CACs. Este fenómeno es bastante evidente en regiones costeras de Venezuela, Brasil y México. El principal problema ambiental causado por estas industrias es la contaminación del medio costero y marino. Además, el desarrollo de esta actividad conlleva la creación de industrias y construcción de grandes infraestructuras que provocan una continua degradación del medio, así como de los ecosistemas asociados (Almeida, 2006).

En cuanto a otro tipo de industria, como la del cemento, destaca su crecimiento de forma acelerada en ALC en las últimas décadas. Los resultados obtenidos en esta investigación hacen pensar que dicha actividad se está localizando, especialmente, en las áreas litorales. La industria cementera ha tenido en países como Panamá y Perú un enorme auge. Mientras que en Panamá se centra en la creación de infraestructuras costeras (como la ampliación del canal) y redes viarias; Perú canaliza la construcción principalmente hacia viviendas y equipamientos (Ficem, 2013). 


\section{Conclusiones. Evolución y tendencias en el modelo de expansión urbana de ALC}

Lo expuesto anteriormente avala, en primer lugar, el interés y gran valor que se concede al resultado obtenido después de cruzar las fuentes de información utilizadas. En efecto, no es común, al menos en la escala regional, vincular las bases de datos estadísticas de población con la información obtenida por sensores remotos. La detallada cuantificación del fenómeno urbano-poblacional de las primeras, ha sido bien complementada por la naturaleza cualitativa de la información observada en las segundas. Difícilmente podría abordarse de otra manera el análisis de las implicaciones de la expansión y crecimientos urbanos respecto del modelo territorial y los ecosistemas costeros marinos circundantes.

Cuadro $\mathrm{N}^{\circ} 8$

Principales resultados para definir el modelo urbano costero de ALC

Datos que reflejan el modelo de urbanización del litoral de ALC

- El número de CACs en ALC se multiplica por 10 en el periodo de estudio (de 42 a 420 entre 1945 y 2014). Suponiendo un aumento del 9 al 20\% con respecto a los datos mundiales.

- Existen 173 CACs en 2014 (41\% de las CACs) consideradas ciudades de borde costero.

- La población en CACs aumenta de 20 a casi 180 millones de personas en el periodo de estudio.

- Las ciudades pequeñas (de 100.000 a 500.000 habitantes) suponen el 40\% de la población en CACs.

- En el litoral se encuentra de media una ciudad cada $9.000 \mathrm{~km} 2$, en el interior ocurre cada $96.000 \mathrm{~km}^{2}$.

-En 2000 había 39 millones de personas en EUM próximos a CACs (100km).

- Actualmente hay 264 CACs que tienen al menos otra CAC próxima (50 km).

- Casi la mitad de la población en CACs se encuentra en bahías y lagunas costeras.

- En la actualidad hay 174 CACs sobre deltas y estuarios.

- La población asociada a arrecifes de coral pasa de 4 a 52 millones en el periodo de estudio.

- El porcentaje de CACs próximas a manglares pasa del 62 al 80\% en el periodo de estudio.

- Las principales ciudades turísticas de ALC se encuentran en el litoral.

- Los principales puertos de ALC tienen CACs asociadas (excepto Freeport y Colón).

- Las CACs asociadas a las explotaciones petroquímicas pasan de suponer el 25 al 30\% del total de CACs.

Fuente: elaboración propia.

La segunda conclusión alude a la diferencia neta entre el esquema urbano costero de ALC y el del resto del mundo. La tendencia de las últimas siete décadas es fácilmente observable: la región americana ha consolidado una red urbana costera de base mucho más amplia en cuanto al número de ciudades (ha multiplicado por 10 el número de sus CACs y ha pasado del $9 \%$ a suponer el $20 \%$ del total mundial). Aunque estas son de un tamaño sensiblemente menor (por debajo de los
500.000 e incluso de los 100.000 habitantes) que las que configuran el modelo mundial. Gracias a este proceso la macrocefalia que siempre ha caracterizado al sistema urbano latinoamericano matiza la tendencia mantenida durante muchas décadas.

En tercer lugar el poblamiento urbano de ALC está corrigiendo en cierta medida su desequilibrio costa-interior: aunque las CACs todavía ostentan su primacía, tanto 
en número como en habitantes, respecto de las continentales o de tierra adentro, las diferencias tienden a suavizarse. Por otro lado, el patrón de ocupación territorial de las ciudades costeras refleja una progresiva y elevada densidad. Y no solo nos referimos a cifras absolutas. La comparación del número de ciudades por cada $10.000 \mathrm{~km}^{2}$ en ámbitos costeros e interiores muestra escenarios territoriales bien diferentes. Por último, el fenómeno conurbatorio se consolida o deja bien sentadas sus bases futuras en la zona costera. Ello se expresa de dos formas diferentes pero complementarias: el $88 \%$ de las CACs de ALC tiene a menos de $100 \mathrm{~km}$ otras entidades urbanas más pequeñas (por debajo de 100.000 habitantes), y un $63 \%$ de las CACs tiene a otras (por encima de los 100.000 habitantes) a menos de $50 \mathrm{~km}$.

La cuarta de las conclusiones extraídas en la investigación es que algunas unidades fisiográficas o ecosistemas costero marinos de gran interés presentan una estrecha relación con la expansión urbana. De hecho sucede que los cuerpos de aguas cerrados o semicerrados, los estuarios y desembocaduras, y otros hábitats críticos, como arrecifes de coral o manglares, coinciden con los ámbitos geográficos o ecosistemas más dinámicos desde el punto de vista urbano. Solo basta recordar, a modo de ejemplo, que el $80 \%$ de las CACs de ALC, y casi las tres cuartas partes de su población (más de 133 millones de personas), viven a menos de $100 \mathrm{~km}$ de un área de manglar. Otra forma de expresar el ritmo de cambio que se registra en el litoral es que, en la actualidad, existe la misma extensión de suelo urbano en las proximidades de los manglares que el área que ocupan estos mismos ecosistemas.

También algunas facetas del desarrollo económico de las CACs han sido analizadas. En este sentido la observación de imágenes facilitadas por sensores remotos precisan que casi el $90 \%$ de las ciudades costeras mayores de 100.000 habitantes disponen de una infraestructura portuaria a menos de 100 $\mathrm{km}$. Incluso el hecho de que, al principio del período estudiado, el número de CACs asociadas a yacimientos petrolíferos fuera de 6 , y en la actualidad se hayan multiplicado por 20, es bastante elocuente.
En cualquier caso, el Cuadro $N^{\circ} 8$ cuantifica varios de los hallazgos más destacados de la evolución reciente del sistema urbano costero de ALC. La conclusión general a la que nos lleva un ritmo tan rápido e intenso de urbanización, y sobre todo en los lugares en los que se ha producido, es que las políticas públicas nacionales de gestión de zonas costeras ya disponen de señales claras respecto a cuáles pueden ser algunas de sus prioridades. Además, se evidencian si se superponen los hallazgos de este estudio con los diferentes escenarios espacio-temporales de vulnerabilidad del litoral de cara a los efectos que ya se evidencian vinculados con el cambio climático.

\section{Referencias bibliográficas}

AGARDY, T.; ALDER, J. \& DAYTON, P. Coastal Systems. In: HASSAN R.; SCHOLES, R. \& Ash, N. (editors). Ecosystems and Human Well-being: Current Status and Trends. Washington: Island Press, 2005, p. 513-550.

ALMEIDA, A. Fases e impactos de la actividad petrolera. Acción Ecológica. In: Manual de Monitoreo Ambiental Comunitario: Acción Ecológica. Quito, 2006.

ANGEL, S.; SHEPPARD, S. \& CIVCO, L. The Dynamics of Global Urban Expansion. London: World Bank, 2005.

ARENAS, P. Manejo Costero y Sostenibilidad en Iberoamérica. Madrid: Editorial Académica Española, 2012.

ARENAS, P. \& GARCÉS, H. Diagnóstico de la gestión del litoral en la República de Panamá. En: Manejo Costero Integrado y Política Pública en Iberoamérica: Un diagnóstico. Necesidad de Cambio. Madrid: CYTED, 2010, p. 71-90.

BÁRCENA, A. Evolución de la urbanización en América Latina y el Caribe en la década de los noventa: desafíos y oportunidades. In: Nueva Agenda en América Latina, 2001, No 790, p. 51-61.

BARRAGÁN, J.M. Medio ambiente y desarrollo de Areas litorales: Introducción a la 
planificación y gestión integradas. Cádiz: Universidad de Cádiz, 2003.

BARRAGÁN, J.M. Reflexiones acerca del futuro de Bahía Málaga (Pacífico colombiano), 2010. Disponible en Internet: http:// hum117.uca.es/grupogial/paginas/proyectos/ informebahiamalaga

BARRAGÁN, J.M. (coordinador). Manejo Costero Integrado en Iberoamérica: Diagnóstico y propuestas para una nueva política pública. Madrid: CYTED, 2012.

BARRAGÁN, J.M. Política, gestión y litoral. Una nueva visión de la gestión integrada de áreas litorales. Madrid: Tebar, UNESCO, 2014.

BARRAGÁN, J.M.; DADON, J.R.; MATTEUCCI, S.D.; MORELLO, J.H.; BAXENDALE, C. \& RODRIGUEZ, A. Preliminary Basis for an Integrated Management Program for the Coastal Zone of Argentina. Coastal Management, 2003, Vol. 31, No 1, p. 55-77.

BARRAGÁN, J.M. \& DE ANDRÉS, M. Analysis and trends of the world coastal cities and agglomerations. Ocean \& Coastal Management, 2015, No 114, p. 11-20.

BARRAGÁN, J.M. y DE ANDRÉS, M. Aspectos básicos para una gestión integrada de las áreas litorales de España: conceptos, terminología, contexto y criterios de delimitación. Journal of integrated coastal zone management, 2016, Vol. 16, № 2, p. 171-183.

BELTRAO, E. Modelando el crecimiento de ciudades medias. Hacia un desarrollo urbano sustentable. Revista de Geografía Norte Grande, 2015, № 60, p.239-243.

BURKE, L.; KURA,Y.; KASSEM, K.; REVENGA, C.; SPALDING, M. \& MCALLISTER, D. Pilot analysis of global ecosystems: Coastal ecosystems. Washington: WRI, 2001.

BURKE, L. y MAIDENS, J. Arrecifes en Peligro en el Caribe. Washington: World Resources Institute, 2005.

CABRERA, A.; GARCÍA, G. y REY, O. El manejo integrado costero en Cuba: un camino, grandes retos. In: Manejo Costero Inte- grado y Política Pública en Iberoamérica: Un diagnóstico. Necesidad de Cambio. Madrid: CYTED, 2010, p. 91-120.

CAVIEDES, V.; ARENAS-GRANADOS, P. y CARRASCO, J.C. Una contribución a la política pública para el manejo costero integrado de Honduras: análisis diagnóstico. Revista de Gestão Costeira Integrada, 2014, № 14, p. 645-662.

COMISIÓN ECONÓMICA PARA AMÉRICA LATINA Y EL CARIBE (CEPAL). América Latina y el Caribe: Evolución del sistema portuario, 1997-2013. Santiago de Chile: CEPAL, 2014, No 330 .

INTERNATIONAL CENTER FOR TROPICAL AGRICULTURE (CIAT). Global Rural-Urban Mapping Project, Version 1 (GRUMPV1): Settlement Points. Palisades. New York: NASA Socioeconomic Data and Applications Center (SEDAC), 2011.

COHEN, J. \& SMALL, C. Hypsographic demography: The distribution of human population by altitud. Proceedings of the National Academy of Sciences of the United States of America, 1998, Vol. 95, N²4, p. 14009 14014.

COlantonio, A. \& POTTER, R.B. City profile Havana. Cities, 2006, Vol. 23, N 1, p. 63-78.

CONSUELO, C.; CARLOS, R. y ÁlVARO, D. Peligros naturales en geositios de interés patrimonial en la costa sur de Atacama. Revista de Geografía Norte Grande, 2010, No 45, p. 21-39.

CREEL, L. Ripple effects: Population and coastal regions. Washington: Population Reference bureau, Measure Communication, 2003.

DADON, J.R. Manejo costero en la República Argentina. In: Manejo Costero Integrado y Política Pública en Iberoamérica: Un diagnóstico. Necesidad de Cambio. Madrid: CYTED, 2010, p. 235-260.

DAHL, A. Island Directory. New York: UNEP, Regional Seas Directories and Bibliographies, 1995, No35. 
DElGadO, A. Guayaquil. Cities, 2013, $N^{\circ} 31$, p. 515-532.

ECOPLATA. Apoyo a la gestión integrada de la zona costera uruguaya del Río de la Plata. Montevideo: Programa de las Naciones Unidas para el Desarrollo (PNUD), Ministerio de Vivienda, Ordenamiento Territorial y Medio Ambiente, International Development Research Centre (IDRC - Canadá), 1999.

FOOD AND AGRICULTURE ORGANIZATION OF THE UNITED NATIONS (FAO). South America. In: The world's mangroves 1985-2005. Rome: FAO, 2007, p. 43-48.

FEDERACIÓN INTERAMERICANA DEL CEMENTO (FICEM). Informe Estadístico 2013. 2013. Disponible en Internet: http://www.ficem.org/estadisticas/informe-estadistico.html

GARCÍA, J.; MORELOCK, J.; CASTRO, R.; GOENAGA, C. \& HERNÁNDEZ-DELGADO, E. Puertorican reefs: research synthesis, present threats and management perspectives. Latin American Coral Reefs, 2003, p. 111 130.

GIRI, C.; OCHIENG, E.; TIESZEN, L.L.; ZHU, Z.; SINGH, A.; LOVELAND, T.; MASEK, J. \& DUKE, N. Status and distribution of mangrove forests of the world using earth observation satellite data. Global Ecology and Biogeography, 2011, Vol. 20, №1, p. 154-159.

GONZÁLEZ, J.; SALINAS, E.; NAVARRO, E.; ARTIGUES, A.; REMOND, R.; YRIGOY, I.; ECHARRI, M. \& ARIAS, Y. The City of Varadero (Cuba) and the Urban Construction of a Tourist Enclave. Urban Affairs Review, 2013, $N^{0} 50$, p. 206-243.

GRIMSDITCH, G.D. \& SALM, R.V. Coral Reef Resilience and Resistance to Bleaching. IUCN, 2006. Disponible en Internet: http:// www.reefresilience.org/pdf/coral_reef_resilience_gg-rs.pdf

GUZMÁN, H.M. Caribbean coral reefs of Panama: present status and future perspectives. Latin American Coral Reefs, 2003, p. 241-274.
HALBOUTY, M. Giant oil and gas fields of the decate 1990-1999. American Association of Petroleum Geologists, 2000.

HARDOY, J. El proceso de urbanización en América Latina. In: La Cultura en América Latina, Monografías, 1974, Vol. 2, p. 25.

HINRICHSEN, D. Coastal waters of the world: Trends, threat and strategies. Washington: Island Press, 1998.

JACKSON, J.B.C.; DONOVAN, M.K.; CRAMER, K.L. \& LAM, V.V. (editors). Status and trends of Caribbean coral reefs: 1970-2012. IUCN, 2014. Disponible en Internet: http://cmsdata.iucn.org/downloads/caribbean_coral_reefs___status_report_1970_2012.pdf

JORDAN, R. y SIMIONI, D. Ciudades intermedias de América Latina y el Caribe: Propuesta para la gestión urbana. Santiago de Chile: CEPAL, 1998.

JORDAN, R. y SIMIONI, D. Gestión urbana para el desarrollo sostenible en América Latina y el Caribe. Santiago de Chile: CEPAL, 2003.

KLAUFUS, C. Watching the city grow: remittances and sprawl in intermediate Central American cities. Environment and Urbanization, 2010, Vol. 22, No 1, p. 125-137.

KOPPRIO, G.A.; BIANCALANA, F; FRICKE, A.; GARZÓN CARDONA, J.E.; MARTINEZ, A.M. \& LARA, R.J. Global change effects on biogeochemical processes of Argentinian estuaries: An overview of vulnerabilities and ecohydrological adaptive outlooks. Marine Pollution Bulletin, 2015, Vol. 91, №2, p. 554-562.

MCGRANAHAN, G.; BALK, D. \& ANDER$\mathrm{SON}, \mathrm{B}$. The rising tide: assessing the risks of climate change and human settlements in low elevation coastal zones. Environment and Urbanization, 2007, Vol. 19, № 1, p. 17-37.

MCGRANAHAN, G.; MARCOTULLIO, P.; BAI, X.; BALK, D.; BRAGA, T.; DOUGLAS, I. \& ELMQVIST, T. Urban Systems. IN: HASSAN, R.; SCHOLES, R. \& ASH, N. (editors). Ecosystems and Human Well-being: Current State 
and Trends. Washington: Island Press, 2004, No 27, p. 796-825.

MONTI, A. y ESCOFET, M., Ocupación urbana de espacios litorales: gestión del riesgo e iniciativas de manejo en una comunidad patagónica automotivada (Playa Magagna, Chubut, Argentina). Investigaciones Geográficas, Boletín del Instituto de Geografía, 2008, №67, pp. 113-129.

MULLIGAN, G.F. \& CRAMPTON, J.P. Population growth in the world's largest cities. Cities, 2005, Vol. 22, № 5, p. 365-380.

MULLINS, P. Tourism Urbanization. International Journal of Urban and Regional Research, 1991, No 15(3), p. 326-342.

OILWATCH. Situación Petrolera en América Latina. Boletín Resistencia, 2004, № 50. Disponible en Internet: http://www.oilwatch. org/boletines-resistencia/437-boletin-resistencia-50

PALMER, M.A.; LIERMANN, C.A.R.; NILSSON, C.; FLORKE, M.; ALCAMO, J.; LAKE, P.S. \& BOND, N. Climate change and the world's river basins: anticipating management options. Frontiers in Ecology and the Environment, 2008, Vol. 6, № 2, p. 81-89.

PÉREZ-CAYEIRO, M.L. \& CHICA-RUIZ, J.A. Evaluation of a programme of integrated coastal zone management: The Ecoplata Programme. Marine Policy, 2015, № 51, p. 527-535.

PROGRAMA DE LAS NACIONES UNIDAS PARA EL MEDIO AMBIENTE (PNUMA). GEO América Latina y el Caribe. Perspectivas del medio ambiente 2003. 2003. Disponible en Internet: http://www.pnuma.org/deat1/pdf/ GEO\%20ALC\%202003-espanol.pdf

PROGRAMA DE LAS NACIONES UNIDAS PARA EL MEDIO AMBIENTE (PNUMA). Perspectivas del medio ambiente: América Latina y el Caribe. GEO ALC 3. 2010. Disponible en Internet: http://www.pnuma.org/geo/geoalc3/

SCHERER, M.; SANCHES, M. \& NEGREIROS, D.H. Gestão das Zonas Costeiras e as Políticas Públicas no Brasil: um diagnóstico. En: Manejo Costero Integrado y Política Pú- blica en Iberoamérica: Un diagnóstico. Necesidad de Cambio. Madrid: CYTED, 2010, p. 291-330.

SCHERER, M.; COSTAB, M.F.; BOSKIC, T.; AZEITEIROE, U.M. \& DIAS, J., A. Integrated Coastal Management in Latin America: the ever New World. Journal of Integrated Coastal Zone Management, 2014, Vol. 14, № 4, p. 663-668.

SEGUINOT, J. La ecología urbana de San Juan (una interpretación geográfico social). Anales de Geografía de La Universidad Complutense, 1996, № 11.150, p. 161-184.

SMALL, C. \& NICHOLLS, R.J. A global analysis of human settlement in coastal zones. Journal of Coastal Research, 2003,Vo. 19, №3, p. 584-599.

TOVILLA, C.; PÉREZ, J. y MINERVA, A. Gestión litoral y política pública en México: Un diagnóstico. En: Manejo Costero Integrado y Política Pública en Iberoamérica: Un diagnóstico. Necesidad de Cambio. Madrid: CYTED, 2010, p. 15-40.

UNITED NATIONS DEPARTMENT OF ECONOMIC AND SOCIAL AFFAIRS (UNDESA). World Population Prospects: The 2012 Revision, Highlights. 2013. Disponible en Internet: https://esa.un.org/unpd/wpp/publications/Files/WPP2012_HIGHLIGHTS.pdf

UNITED NATIONS DEPARTMENT OF ECONOMIC AND SOCIAL AFFAIRS (UNDESA). World Urbanization Prospects: The 2014 Revision, Highlights. 2014. Disponible en Internet: https://esa.un.org/unpd/wup/Publications/Files/WUP2014-Highlights.pdf

UN-HABITAT. De la urbanización acelerada a la consolidación de los asentamientos humanos en América Latina y el Caribe: El espacio regional. Santiago de Chile: UNHABITAT, 2000.

UN-HABITAT. Estado de las Ciudades de América Latina y el Caribe 2012. Rumbo a una nueva transición urbana. México: UNHABITAT, 2012.

UNITED NATIONS ENVIRONMENT PROGRAMME (UNEP). Marine and coas- 
tal ecosystems and human well-being: A synthesis report based on the findings of the Millennium Ecosystem Assessment. 2006. Disponible en Internet: http://www. unep.org/publications/search/pub_details_s. asp?ID=3792

WORLD TOURISM ORGANIZATION (UNWTO). Annual report 2013. 2014. Disponible en Internet: http://www2.unwto.org/es/ node/40663

VALIELA, I.; BOWEN, J.L. \& YORK, J.K. Mangrove Forests: One of the World's Threatened Major Tropical Environments. BioScience, 2001, Vol. 51, № 10, p. 807-815.

VALLEGA, A. Fundamentals of integrated coastal management. Dordrecht: Kluwer Academic Publishers, 1999.

VAN VUUREN, D.P.; ISAAC, M.; KUNDZEWICZ, Z.W.; ARNELL, N.; BARKER, T.; CRIQUI, P.; BERKHOUT, F.; HILDERINK, H.; HINKEL, J.; HOF, A.; KITOUS, A.; KRAM, T.;
MECHLER, R. \& SCRIECIU, S.The use of scenarios as the basis for combined assessment of climate change mitigation and adaptation. Global Environmental Change, 2011, Vol. 21, $N^{\circ} 2$, p. 575-591.

VERÓN, E. Lógicas territoriales, representaciones y gestión de un espacio fragmentado en torno a problemáticas socioambientales. Estudio comparado de los distritos de La Costa, Pinamar, Villa Gesell, General Lavalle y General Madariaga. Bahía Blanca: Tesis de Doctorado en Geografía, UCA (España) y UNS (Argentina), 2014.

WILMSMEIER, G.; MARTINEZ, I. \& FIESS, $\mathrm{N}$. Regional hub port development- The case of Montevideo, Uruguay. International Journal of Shipping and Transport Logistics, 2011, Vol. 3, No 4, p. 475-493.

WORLD BANK. Population 2013. World Development Indicators Database. 2014. Disponible en Internet: http://data.worldbank.org/ 
